\title{
Evaluation of Various Indications of Caesarean Section in a Tertiary Care Hospital, Bangladesh
}

\author{
Dr. Nazneen Ahmed ${ }^{1 *}$, Dr. Zinnatun Nahar ${ }^{2}$, Dr. Nadeed Masih ${ }^{3}$ \\ ${ }^{1}$ Dr. Nazneen Ahmed, Associate Professor, Department of Obstetrics \& Gynecology, HFRCMCH, Dhaka, Bangladesh \\ ${ }^{2}$ Dr. Zinnatun Nahar, Resident, Department of Obstetrics \& Gynecology, HFRCMCH, Dhaka, Bangladesh \\ ${ }^{3}$ Dr. Nadeed Masih, Intern Doctor, HFRCMCH, Dhaka, Bangladesh
}

DOI: $10.36348 /$ sijog.2021.v04i04.016 $\quad$ | Received: 19.03.2021 | Accepted: 25.04.2021 | Published: 30.04 .2021

*Corresponding author: Dr. Nazeen Ahmed

\section{Abstract}

Background: The incidence of caesarean section varies from hospital to hospital and from community to community and it is much more in tertiary care hospital because of referral from other centres. Objective: The objective of this study was to investigate the caesarean section rates by evaluating the indications as per modified Robsons criteria and to determine the area of concern that requires maximum focus to decrease the overall caesarean section rate. Methodology: This crosssectional retrospective study was conducted over a period of one year from January 2019 to December 2019 in the department of Obstetrics and Gynecology at Holy Family Red Crescent Medical College Hospital, Dhaka, Bangladesh. Result: Total number of deliveries for one year was 891. Out of them 162 were normal vaginal delivery and 729 were by caesarean section. Overall maximum caesarean section was contributed by group five Robsons criteria. Conclusion: Robsons ten group classification provides an easy way in collecting information about the indication of $\mathrm{C} / \mathrm{S}$ and there by caesarean section rate. It is important that efforts to reduce the overall caesarean section rate should focus on reducing the primary caesarean section and increasing vaginal birth after the caesarean section.

Keywords: Caesarean section, hospital, rate, Robsons, overall, community.

Copyright (C) 2021 The Author(s): This is an open-access article distributed under the terms of the Creative Commons Attribution 4.0 International License (CC BY-NC 4.0) which permits unrestricted use, distribution, and reproduction in any medium for non-commercial use provided the original author and source are credited.

\section{INTRODUCTION}

The cesarean section plays an important and vital role as some of the deliveries are never possible through the vaginal route without threatening the life or health of the mother or baby. Cesarean section is one of the most common major surgical procedures in health care service. The epidemic of cesarean section deserves serious international attention due to the reason for immediate concern. Recent advancement of anaesthesia, antibiotics, antiseptic and aseptic technique, blood transfusion facilities and safe surgical technique reduces the morbidity and mortality rate of cesarean section. Still, the operation is not totally free of hazards. So judgment has to be exercised in deciding which cases should be delivered by cesarean section. The consensus recommendation is $10 \%-15 \%$ by WHO [1]. Many are questioning the recommended optimal cesarean section rate by suggesting that lowering the rate may be dangerous. Efforts to bring down the rate have failed and it is on a steady rise. According to the world health respect, there is no justification or any reason to have a cesarean section rate higher than 10 $15 \%$. There are various reasons for increase caesarean section rate over the last 40 years which includesrelatively safer surgical procedure, medico-legal litigations, maternal choice, advance age of women giving birth, obesity and various co-exciting medical conditions making pregnancies a high risk one. Common indications include- fetal distress, prolonged labor, malpresentation, multiple gestations, previous section, and a cesarean section on choice. Robson classification [2] is a well-standardized system of reporting cesarean section and it is now universally accepted.

\section{METHODOLOGY}

This cross-sectional retrospective study was conducted over a period of one year from January 2019 to December 2019 from the hospital records in the department of Obstetrics and Gynecology in HFRCMCH which is a tertiary care hospital in Dhaka, 
Bangladesh. Collected data were classified according to modified Robson's criteria for cesarean section. Relevant obstetric data as parity, mode of previous deliveries, previous cesarean section indication, and gestational age were noted.

\section{RESULTS}

During the study period, a total of 891 patients were delivered. 729 patients had undergone $\mathrm{C} / \mathrm{S}$ with a $\mathrm{C} / \mathrm{S}$ rate being around $81.81 \%$. The majority of the $\mathrm{C} / \mathrm{S}$
$(29.18 \%)$ were performed electively due to $\mathrm{H} / \mathrm{O}$ previous $\mathrm{C} / \mathrm{S}$ before labor which is included in Robson's group five. A maximum number of patients were between $21-30$ years $(54.86 \%)$ and $35.8 \%$ were primipara. The majority of the patients $(80 \%)$ belong to the urban area. Previous C/S (29.18\%) was the commonest indication, followed by fetal distress were $21.5 \%$.

Table-1: Demographic Profile \& General Findings of the Participants ( $=891$ )

\begin{tabular}{|l|l|l|}
\hline Variables & $\mathbf{n}$ & \% \\
\hline Mode of Delivery & & \\
\hline Caesarean Section & 729 & 81.82 \\
\hline Vaginal Delivery & 162 & 18.18 \\
\hline Location & & \\
\hline Urban & 713 & 80.0 \\
\hline Rural & 178 & 20.0 \\
\hline Age group & & \\
\hline $21-30$ years & 489 & 54.86 \\
\hline $31-40$ years & 244 & 27.43 \\
\hline$>40$ years & 158 & 17.71 \\
\hline
\end{tabular}

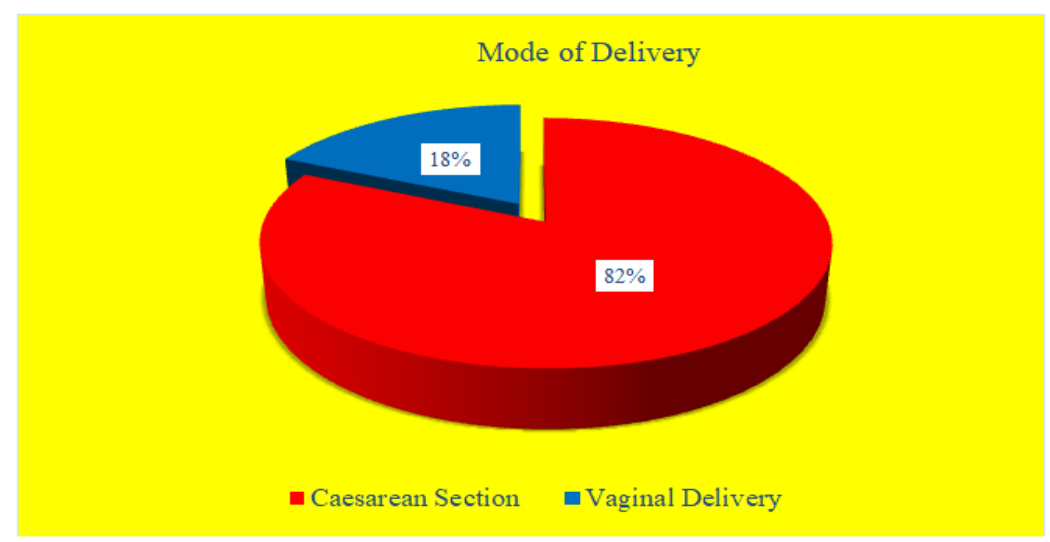

Fig-1: Mode of Delivery

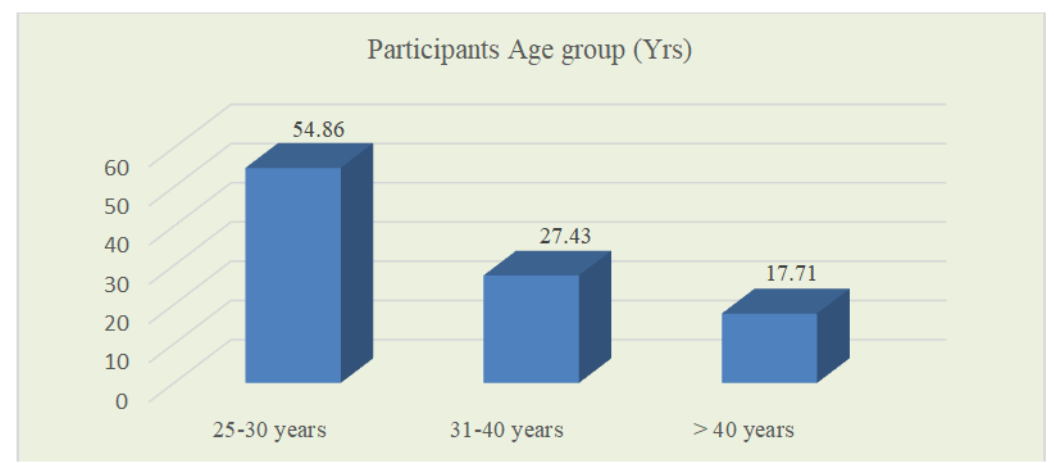

Fig-2: Participants Age Group 
Nazneen Ahmed et al; Sch Int J Obstet Gynec, Apr. 2021; 4(4): 173-176

Table-2: Classification of Caesarean Section according to Modified Robsons classification $(\mathrm{N}=729)$ Groups

\begin{tabular}{|l|l|l|}
\hline Variables & n & $\%$ \\
\hline Nulliparous, single, cephalic $>37$ weeks in & & \\
\hline Spontaneous labor & 14 & 1.92 \\
\hline Induced & 7 & 0.96 \\
\hline CS before labor & 130 & 17.83 \\
\hline Multiparous (excluding previous CS) single, cephalic, >37 weeks in & & \\
\hline Spontaneous labor & 40 & 5.49 \\
\hline Induced & 32 & 4.39 \\
\hline CS before labor & 95 & 13.03 \\
\hline Previous CS, single, cephalic>37 weeks & & \\
\hline Spontaneous labor & 10 & 1.37 \\
\hline Induced & 0 & 0.00 \\
\hline CS before labor & 230 & 31.55 \\
\hline All nulliparous breeches & & \\
\hline Spontaneous labor & 0 & 0.00 \\
\hline Induced & 0 & 0.00 \\
\hline CS before labor & 12 & 1.65 \\
\hline All multiparous breeches( including previous CS) & & \\
\hline Spontaneous labor & 0 & 0.00 \\
\hline Induced & 0 & 0.00 \\
\hline CS before labor & 11 & 1.51 \\
\hline All multiparous pregnancies (including previous CS) & & \\
\hline Spontaneous labor & 2 & 0.27 \\
\hline Induced & 0 & 0.00 \\
\hline CS before labor & 9 & 1.23 \\
\hline All abnormal lies including previous CS, excluding breech & & \\
\hline Spontaneous labor & 0 & 0.00 \\
\hline Induced & 0 & 0.00 \\
\hline CS before labor & 4 & 0.55 \\
\hline All single, cephalic, <36 weeks (including previous CS & & \\
\hline Spontaneous labor & 2 & 0.27 \\
\hline Induced & 5 & 0.69 \\
\hline CS before labor & 90 & 12.35 \\
\hline & \\
\hline
\end{tabular}

\section{DISCUSSION}

Increased rate of $\mathrm{C} / \mathrm{S}$ has become in focus when the rate of complication in form of invasive placentation begun to rise in number. Yadav RG et al., [3] did examine caesarean section rates by using Robson ten group classification system from 2004 to 2013. Out of 40,086 deliveries in this center caesarean section rate was $25.17 \%$ In 2015 , WHO proposed the use of the Robson classification as a global standard for assessing, monitoring, and comparing caesarean section rates both within healthcare facilities and between them. Five basic obstetric characteristics based on the categories that are routinely collected in all materials like a previous caesarean section, the onset of labor parity, number of fetuses, gestational age, and fetal presentation. In Yadav RG study, they found that group one had the highest contribution followed by group five. While in our study, we found that group five had a maximum contribution. It reflects the centre variation and also the type of referral the center faces. In our study, out of 891 Antenatal patients admitted to our centre, 729 were by caesarean section. According to percentage analysis, it is $81.81 \%$. This increased rate of caesarean section was probably due to most patients were referred from various centers as our hospital is a well-equipped tertiary care hospital. Regarding the indications, most patients fall into group five followed by group two as these patients were already selected for caesarean section. Induction followed by caesarean section rate was very low (Total 32). Many patients had undergone caesarean section by their own choice which was not included in Robson's classification. Our part was to counsel the patients, but we could not ignore their own choice. At our centre, it is routine policy to have an elective caesarean section in IVF conceived patients owing to the amount of mental and financial burden the patients had undergone which does not provide even a small window of slightest risk to the baby. Also in most of the IVF conception, multiple pregnancy rate was more and ultimately caesarean section as well. Once a caesarean, always a caesarean holds true in our study. Mc. Carthy FP et el., [4] also found in their study of 5833 women in Australia and found that women of group five were the single greatest 
Nazneen Ahmed et al; Sch Int J Obstet Gynec, Apr. 2021; 4(4): 173-176

contributor to both elective and total caesarean section rates. The need of the hour is to reduce first or primary caesarean section and then only we can reduce a repeat caesarean section and group five was the highest contributor followed by group one in a retrospective study by Paul RH, Miller DA [5]. Das V, Kumar N, Kumari V, Agarwal et al., [6] analyzed the trend of caesarean section in the Indian population from 1999 to 2011. Group five again emerged as the most significant contributor of caesarean section rate followed by group one and two. WHO conducted a multi-country survey in 21 countries to study the use of the Robson classification to assess caesarean section trends. Strategies to reduce the frequency of the procedure should include avoidance of medically unnecessary primary caesarean section. The patient's age factor was not included in Robson's criteria though many of our cases were undergone caesarean section due to adolescent pregnancy and also elderly Prim gravida. In our center we did some caesarean section due to various medical disorders, which were also not included in Robson's criteria.

\section{CONCLUSION}

Robson's 10 group classification provides an easy way of controlling information about caesarean section rate. A detailed analysis of 10 groups helps to detect the causes of Increased caesarean section rate. It is important that efforts to reduce the overall caesarean section rate should focus on reducing primary caesarean section rate and also increasing Vaginal birth after caesarean section. A better effort in reducing relatively preventable primary caesarean section need enforcement which includes preventing failed induction by a better induction protocol, allowing vaginal birth after primary caesarean section, wait for spontaneous onset of labor up to 41 weeks and then induction, practicing external cephalic version for breech presentation and transverse lie, use of low forceps or ventouse for second-stage delay, allow the second stage 3 hours in nulliparous before saying arrest in the second stage. The further important measure includes practicing partograph WHO checklist and easy availability of epidural analgesia which can reduce caesarean delivery due to maternal distress.

\section{REFERENCES}

1. Sexual and reproductive health, WHO statement on caesarean section rates, Publication date: April 2015 , https://www.who.int/reproductivehealth/publicatio ns/maternal_perinatal_health/cs-statement/en/

2. Sexual and reproductive health, Robson Classification: Implementation Manual, Publication date: 2017 ,

ISBN: 978-92-4-151319-7. https://www.who.int/reproductivehealth/publicatio ns/maternal_perinatal_health/robsonclassification/en/

3. Yadav, R. G., \& Maitra, N. (2016). Examining Cesarean Delivery Rates Using the Robson's Tengroup Classification. Journal of obstetrics and gynaecology of India, 66(Suppl 1), 1-6. https://doi.org/10.1007/s13224-015-0738-1

4. Mc. Carthy FP et el; Hypertension in pregnancy, Obstetrics, Gynecology \& Reproductive Medicine, ISSN: 1751-7214, Vol: 19(5),2009, Page: 136-141

5. Paul, R. H., \& Miller, D. A. (1995). Cesarean birth: how to reduce the rate. Am J Obstet Gynecol. 172(6):1903-1911.

6. Das, V., Kumar, N., Kumari, V., Agarwal, A., Pandey, A., \& Agrawal, S. (2017). Increasing rates of cesarean section, an upcoming public health problem: an audit of cesarean section in a tertiary care center of North India based on Robson classification. International Journal of Reproduction, Contraception, Obstetrics and Gynecology, 6(11), 4998-5002. 